\title{
The impact on my study and personal life of Middle Childhood \& Adolescent Development
}

\author{
Fatema Abdul Latif Al-Thawadi
}

\section{Zayed University}

Learning and Teaching in Higher Education: Gulf Perspectives

Vol 3 No 1, January 2006

\section{Introduction}

When you are studying a course do you think mainly about how you could get full marks in it? Maybe you say to yourself at the beginning of the semester that you will try your best, but this changes by the end to just wanting to pass! If you haven't said such a thing may be you have heard it. I wish to share with you my experiences of studying in one course at Zayed university, and how I ended by saying "I learned a lot" and "I enjoy my studies"? I took Education 309: Middle Childhood \& Adolescent Development in 2004. The course focused on physical, cognitive, and psychosocial development in both middle childhood (age 7-12) and adolescence (age 13-17). I learned a lot from this course that will help me in my career and in my personal life. In this article I will talk about what I learned and how I applied it to my life. First, I will talk about what I learned in the course; then I will share some study advice.

\section{Resources}

I learned a lot in this course about how to find information. For example, Professor Dawn asked each student on day one of the course to go to the library to search for a book of her choice on middle child or teenage development. This made me excited to study the course topic as I found many interesting books in the library. Next, she asked us to write a brief paragraph about our book and cite it in Blackboard on the discussion board. As a result, by the end of the first week we had a collection of books related to our subject with a brief paragraph on it since it we cited it on Blackboard so anyone could access it. Also, in Blackboard we had a section for useful links from internet websites related to our course topics. Anyone including the students could suggest links. Moreover, we were introduced to peer reviewed journal articles that contain information on the latest experiments and findings in developmental psychology, and we had to cite journal articles in our class research reports. One of the most exciting ways I learned for collecting information was by interviewing people about their middle to teen development experiences. I wrote four biographies for this course and learned a lot from this! In addition, Professor Mc Bride asked us in our reports to cite research that supports the person's experience. Overall, this course taught me how to use more than just the textbook to learn!

\section{Some Of My Favorite Topics}

\section{1) Obesity:}

We studied a very serious problem of middle childhood which is obesity. Specifically, in my country, the United Arab Emirates (UAE), children suffer from obesity. In class, we talked about the reasons for childhood obesity. For example children don't have enough physical activity in their daily life; furthermore, the UAE family lifestyle has changed so we now hire many housemaids and cooks which means that our children do not help with chores, and instead spend many hours in front of the TV. Also, children go to school by bus or car so they no longer walk to school; they also spend a lot of time playing computer games instead of going outside. In addition, parents allow their children to eat fast food instead of healthy food. In class, we had many discussions about what parents could do to reduce childhood obesity. Examples include giving children responsibilities in the home so children watch less TV, and also parents should not buy fast food. In my opinion, parents need to be a good model by practicing sports and eating healthy food. For myself, I now encourage my little brothers to do sports such as riding their bicycles and playing football outside rather than watching TV. I will also play with them more rather than just watch TV with them. I have also started walking more so they will have a role model of good, healthy behavior.

\section{2) She can do it!}

It was very encouraging to learn that there are few to no gender differences in what boys and girls can physically do as children. I learned that it is the environment which makes girls believe that they are weak and that they cannot do physical activity or sports as well as boys can! Why can't I give my daughter a ball instead of a Barbie doll? Why is she not expected to play football or basketball and is instead told to sew? Are girls not physically able to play? There is no reason! Girls can play sports! It is culture that tells us girls should be quiet and to not get physical. As a future Mom and teacher, I am going to help girls do more sports by making them aware of sport's benefits. I will be a good model for them to show them that we can do it. Moreover, I will encourage 
them to join clubs or to practice sports, even in their home. I plan to introduce them to useful types of sports and let them choose what they prefer. I think indoor sports will be popular. In my classes, I could put the girls in groups or in pairs and have a sports competition. There is a lot I can do to teach girls to do sports.

\section{3) It is important to READ!}

I like reading a lot and I think after taking this course, it was because my father encouraged me to read from an early age by bringing me many books. I believe that reading is a powerful skill.

In this course I liked learning about the relationship between reading and cognitive development in middle development. According to the course textbook, children gain about 14, 000 words by age 6 and this number increases to about 30,000 words by adulthood. By teaching and encouraging children to read, we will help them to write stories, poem, diaries, jokes, etc. As I see it, reading can help children improve their language skills and improve their imagination; as a result it will make them creative.

In the past, I thought that when a child can't read a word we should say the word for the child; but Prof. Mc Bride showed us that the right way to teach children to read is to make them try and sound the word by themselves first. It is important to give the child enough time to recognize the letters and sound out the word: we have to let children try before we jump in with answers, or else the children will give up and wait for the adult to give the answers. I noticed that most teachers and adults don't give the child even a few seconds to read or spell a new word!

Since Prof. McBride's course, I have started reading with my little brother Ali, who is in grade two. In order to improve his reading skills, I started to provide suitable stories at home to encourage him to read more. I try my best not to say the words aloud to him when he can't spell them. I now give him time to recognize the letters and spell the word by himself. Believe me it's not easy thing to do but he is becoming a better reader and I like that! A secret: I have trained myself to count to 20 before I offer help. But instead of giving him the answer, I try questions Prof. McBride gave us such as, "What is this letter?" " How does it sound if these two letters come together?" My advice to teachers and parents: Please be patient when helping your child to read. Give your child time. Help your child by asking questions that give clues to the right answer. Stay positive and don't give up when a child has trouble saying a new word.

\section{4) Stop! Don't judge}

Many times when we see a person do something bad, we judge the person in a negative way. For example if a boy doesn't do his homework, someone might say "all boys are lazy and don't do their homework". However, in this EDC 309 course, I learned that this boy might have a specific problem that prevents him from doing his homework. As a student who will be a teacher one day, I have learned not to judge bad behavior because we need to know the facts. Instead, we should stop and ask "Why did the person do that ?" Maybe this boy can't see the homework from the board, or maybe he is very slow at copying material from the board so he never had a chance to copy the homework. I can solve the problem with this boy quickly if I take the time to ask why and not judge the behavior as bad. My advice: Try this method - don't judge others! Stop and ask why.

\section{Studying tips:}

In her syllabus, Professor Dawn gave us special studying tips because we were going to learn a lot in her class. To succeed, a student really needs to manage her time and use specific study strategies ( See appendix 1). Here are my five study tips from the course.

\section{A) Memory skills:}

Here are some things Prof. Dawn taught us. First of all we learned to recognize the way we learn and remember information the best. For example, if I am an auditory learner then I need to turn the information to sounds and say it aloud to myself. Or if I am a visual learner then I should turn the information to pictures or put words put on index cards. Moreover, in our studying about childhood metacognition we talked about many other strategies for remembering that we can teach children. Maybe you can try these. These are rehearsal, elaboration rehearsal, selections, method of loci, peg word system, organization, and SQR4.

\section{B) SQR4}

I think this study method works $100 \%$ and here is how you do it:

Survey: Scan the pages and look for the headings. Skim the text just for interesting stuff.

Question: Turn the heading into questions.

Read: Read the paragraph to answer the question.

Recite: Recite the answer to the question.

Review: Review the answers (re read the paragraph).

Relate: Relate the answer to something you already know and then move to the next paragraph and start all over again with step S.

C) Use Blackboard:

I like using Blackboard because it helped me to get organized and it helped me study. Reasons why I like Blackboard are:

- We could get course information and handouts anytime we wanted.

- We had a specific section for internet websites.

- There were weekly course announcements. 
- We discussed many topics in the "discussion board" which I liked because by using discussion board, I can read all students' ideas and it gives students a chance to give examples and response to each other. Also, this will give us a chance to read many opinions and views on one issue while in class time we can't listen to all views as we are limited in time. Some of the topics on the discussion board were:

- Q \& A forum: area where students are allowed to ask any question in this course without showing their names and the professor will answer it.

- Library books- of interest you.

- Candy Banned in Canteens? Yes or No? Why?

- Attention Deficit Disorder

- Abuse

Here is a sample from our discussion board: (see appendix 2 for more samples)

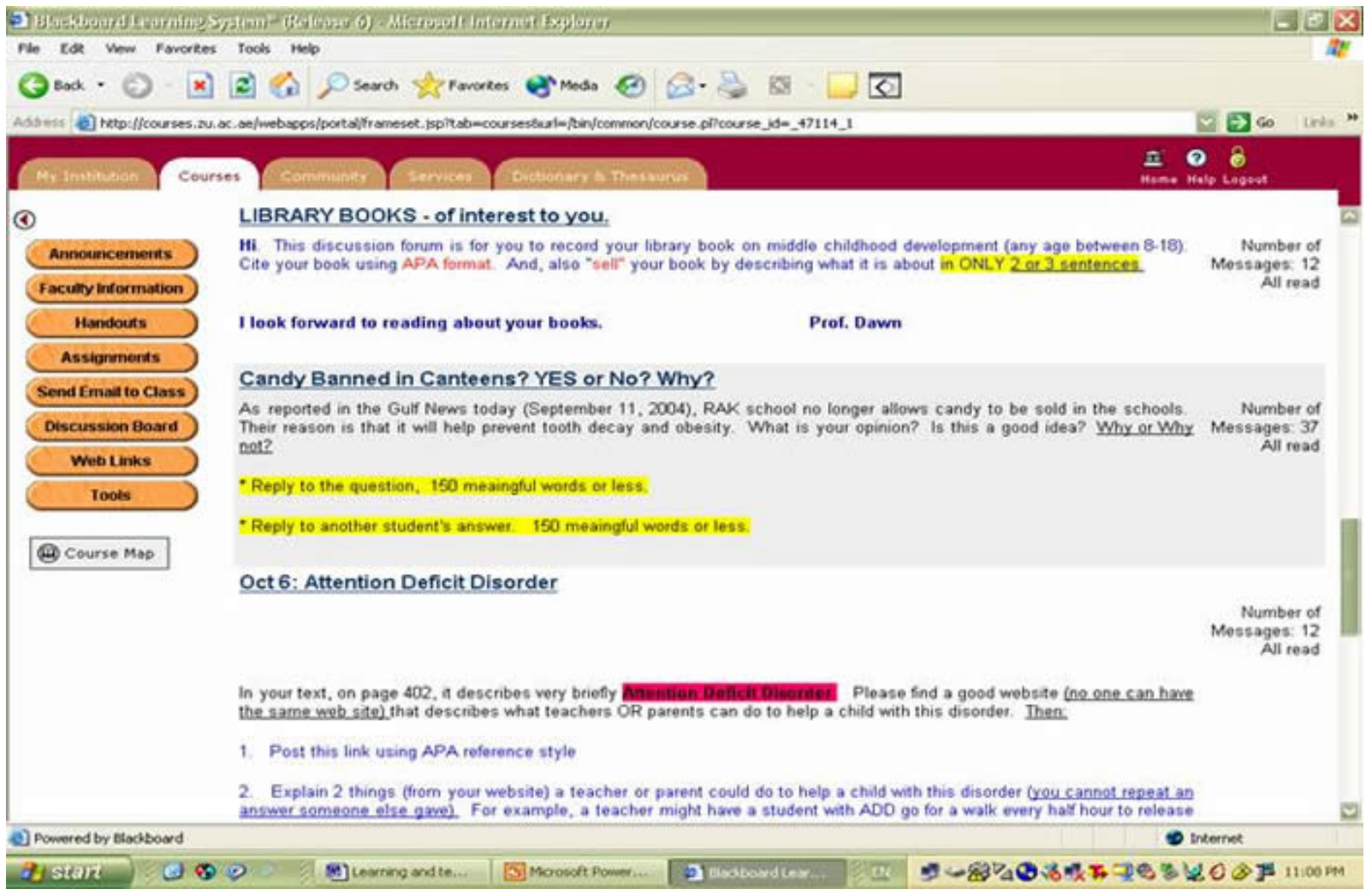

D) Get Feedback:

After each quiz I set an appointment with Prof. McBride to help me understand the questions I got wrong. I brought my textbook to her office to find the answer so I could remember my mistakes in order to not do it again. My advice: Go talk to your professor and ask for help so you can learn more. 
E) Manage deadlines- Use a calendar!

The most difficult thing was to complete the assignments on time and meet Prof. Dawn's standards. It required reviewing our class material on our own time and on a regular basis. In addition, my advice is to start your papers early: don't delay it until two or three days before the deadline. Also use a calendar and schedule everything you have to do, even small things, in the day timer. Make a to-do list for every day. It really helps!

F) Be flexible:

We had a sudden long break in the middle of our course because of $\mathrm{H}$. H Sheikh Zayed's death. We were very sad and shocked. After 3 weeks off we returned to our studies with something missing in our life. We had to come to school at the weekend to complete our semester hours. This put pressure on our time and made us tired; however, being flexible to the changes in the semester will help you stay positive and focused.

\section{Conclusion}

I learned many other things that I have not mentioned in this article. If you try to do some time management and be serious in applying most of the study tips to your academic life, you will work hard but will also learn many things to help you in your life. Try to apply some of them with your friends or your class group in order to encourage each other. I am looking forward to the day that all of us enjoy our studying and do our best without any stress or fear from bad experiences, because the unsuccessful experiences will teach us how to succeed next time. And best of all, we will say at the end of the course "I really learned something!"

\section{Appendixes}

\section{(Appendix \#1)}

\section{STUDY TIPS by Prof. Dawn McBride 1}

"The will to succeed is important, but what is more important is the will to prepare." Basketball Coach Bobby Knight as quoted by L.M. Boyd

Don't wait for an exam to study. You will retain a lot more if you study following each class session, rather than cramming just before an exam. More importantly, while the class is fresh in your mind, you will be better able to identify ideas that need clarification, and to ask me about them. http://webhost.bridgew.edu/jhayesboh/not13th/studytip.htm

Emphasize understanding. Memorization of your notes is not effective if you do not fully understand them. Both during class and during your reading, be sure you understand what you are hearing/seeing. Keep a sheet of paper handy to write down questions to ask the instructor, your tutor, or study partners. http://webhost.bridgew.edu/jhayesboh/not13th/studytip.htm

ON YOUR OWN

- Purchase a day planner \& a 8-12 month poster size wall calendar .... RECORD all the quiz/exam dates (and assignment due dates) in large colorful print. As well, indicate two weeks and one week before each quiz/exam, to remind you of the upcoming due dates.

- Create a study schedule for 7 days of the week ... plan for $3-4$ hrs of studying for every hour spent in class. Post this schedule in 3-4 different places and use SELF-DISCIPLINE to stick to it. NO EXCEPTIONS.

- Create index cards for LECTURE NOTES and READINGS. Side A: Record an important question (typically, a heading turned into a question); SIDE B: Record the answer \& page \# to get more information.

- use the cards daily by carrying the cards with you (tied with an elastic band). Review the cards as you walk somewhere, when you are in the bathroom, when you are at dinner, as you get ready for bed. REVIEW, at minimum, AT LEAST 5-15 CARDS PER DAY -

- Set aside 15 minutes at the end of your study time to review where you are on your various projects and to plan the next day.

- Routinely ask yourself, "What's the purpose of this detail?" and "Does it make sense?"

GET ORGANIZED ... success feels better than failure, so plan accordingly .......

- If not organized, then you always seem to have too many things to do \& you can't get going on any of them.

- Write down all of the academic tasks you have to do, breaking them into their component smaller steps wherever possible.

- Every weekend, make a realistic plan for the upcoming week.

- Every night, make a realistic plan for the next day.

- Don't make your plans too ambitious, or you will always be failing to get through your list. WHILE IN CLASS .......

- Sit toward the front of the class to help you focus.

- In class, listen for emphasis and examples. Take a thorough set of notes; you'll be thankful at test time.

- Don't understand something? Then, ask me right away before you forget or put it off. USE THE SQR4 METHOD .... 
- This study method has been proven over and over again, that it works! Use it!

- Go to the excellent SQR4 web site: http://www.umiss.edu/depts/asc/study/sqr3.html LOCATION .....

- In your study environment, keep the clutter controlled, so your area will be a much more pleasant place to live and you will not be as likely to notice when you have NOT had a chance to dust, make the bed, do the laundry etc

- Clutter - Get everything off your desk except the work that you're doing.

- Find a place that is relatively free of distractions.

- Privacy - Find ways to eliminate unwanted interruptions.

- Establish guidelines for quiet times for yourself, or use the libraries, study rooms, or empty classrooms.

- Remember don't study in front of the TV, it is very DISTRACTING!!!

- Comfort - Watch your posture and support. Avoid drowse-inducing_positions. MONITOR YOUR COMPREHENSION....

- You can only remember and fully use ideas that you understand.

- Find ways to monitor your comprehension. Get in the habit of saying to yourself, "Do I understand this?"

- Always check the logic behind the ideas, i.e., do things happen in a way that you would predict?

If you can see the logic in something, you are much more likely to be able to reconstruct that idea even if you cannot immediately recall

- Look out for anything that seems counter-intuitive to you; you are less likely to remember something that does not seem logical or is something that you would not agree with.

- Evaluate your own comprehension by bouncing your thoughts about a course against those of other students.

GET ENERGIZED: GET RID OF THE JUNK FOOD - EXERCISE - SLEEP...

- Comprehension and memory are affected by stress and fatigue. When you're hungry, tense, or tired your brain can't function at its full potential.

- It's especially crucial to eat well, exercise, and get adequate sleep during exam periods. Try to get at least 8 hours of sleep regularly and at least 7.5 hours during exams if you can.

- Time of day - People have differing patterns of high and low energy throughout the day. Know your own patterns and plan your work accordingly.

\section{REPETITION....}

- Use index cards ... as the more times you go over something, the better your memory will be of that info

- Each time you go through something, try to find a different angle so that you are not just repeating exactly the same activity so you can transfer what you are learning to long-term memory. TEST TAKING TIPS...

- Don't lose marks because of test-writing errors such as misreading a question or running out of time.

- Think through specific strategies to tackle different types of tests (e.g., multiple-choice, short answer, etc).

- Carefully read instructions, budget time to marks, and do less difficult questions first to build confidence.

\section{SEEK SUPPORT FROM THE UNI COUNSELLOR}

- test anxiety

- procrastination problems

- poor motivation rfeeling "blue"

- life stress

- can't concentrate

the following information was compiled by professor dawn mcbride - psychology

HAPPY STUDYING !

STUDY HABIT SELF-ASSESSMENT

( by professor Dawn McBride)

I study best when ....

I learn best by ....

One thing I hate about studying is ....

What I find the most difficult about studying is....

What gets in the way of me studying is......

What I really need to do to improve my studying methods is to ....

Studying takes time away from ....

I wish studying was ....

I have a lot of pressure on me to ....

I think my self-discipline for studying is ..

The hardest distraction, when studying, to deal with is....

I think I could improve my studying methods by .......

Deep in my heart, I know that to improve my studying, I need to ....

The reward I give my self for studying is.... 
I am the type of student that ....

\section{(Appendix -\#2)}

screenshots from our course blackboard.

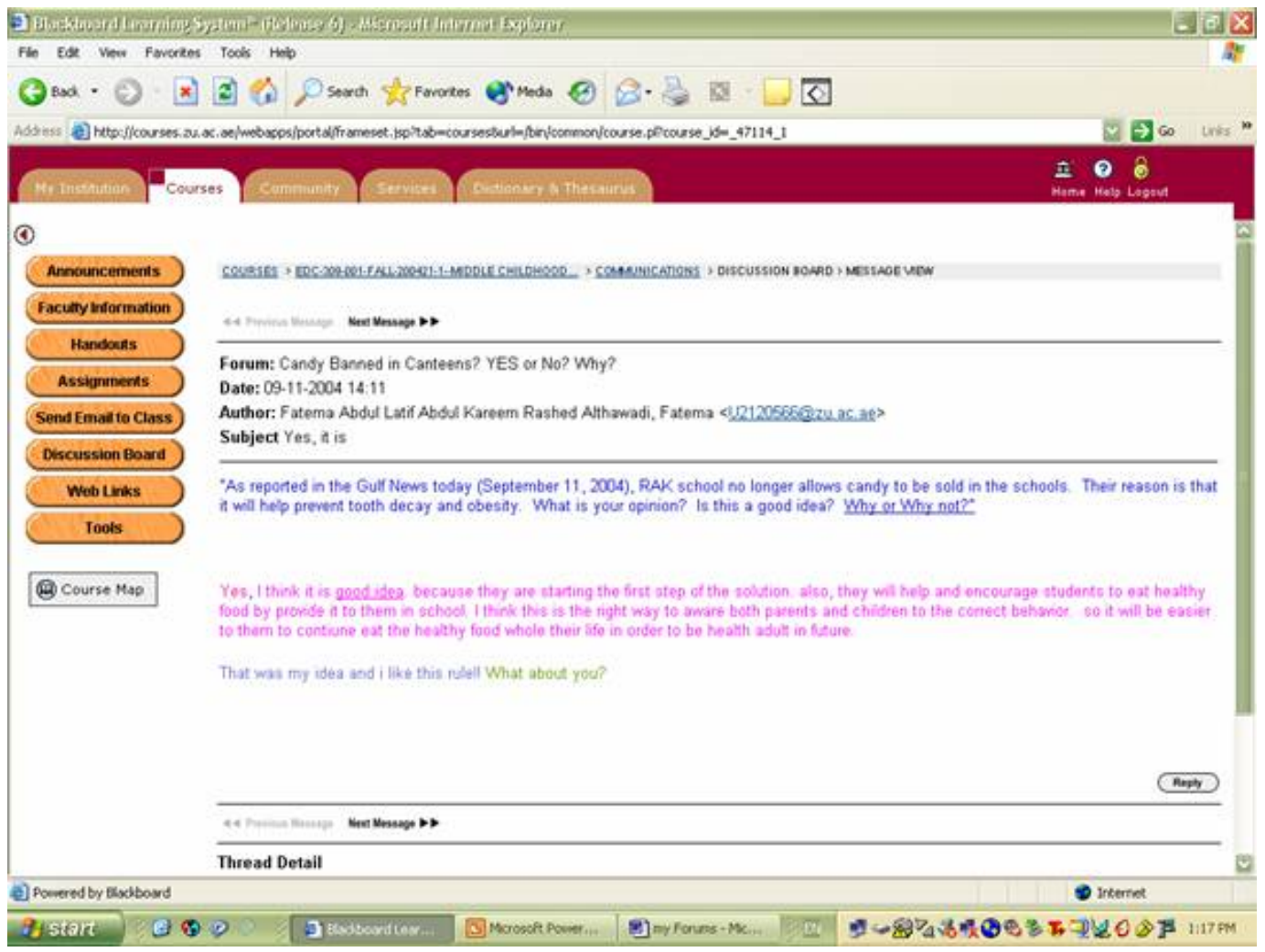

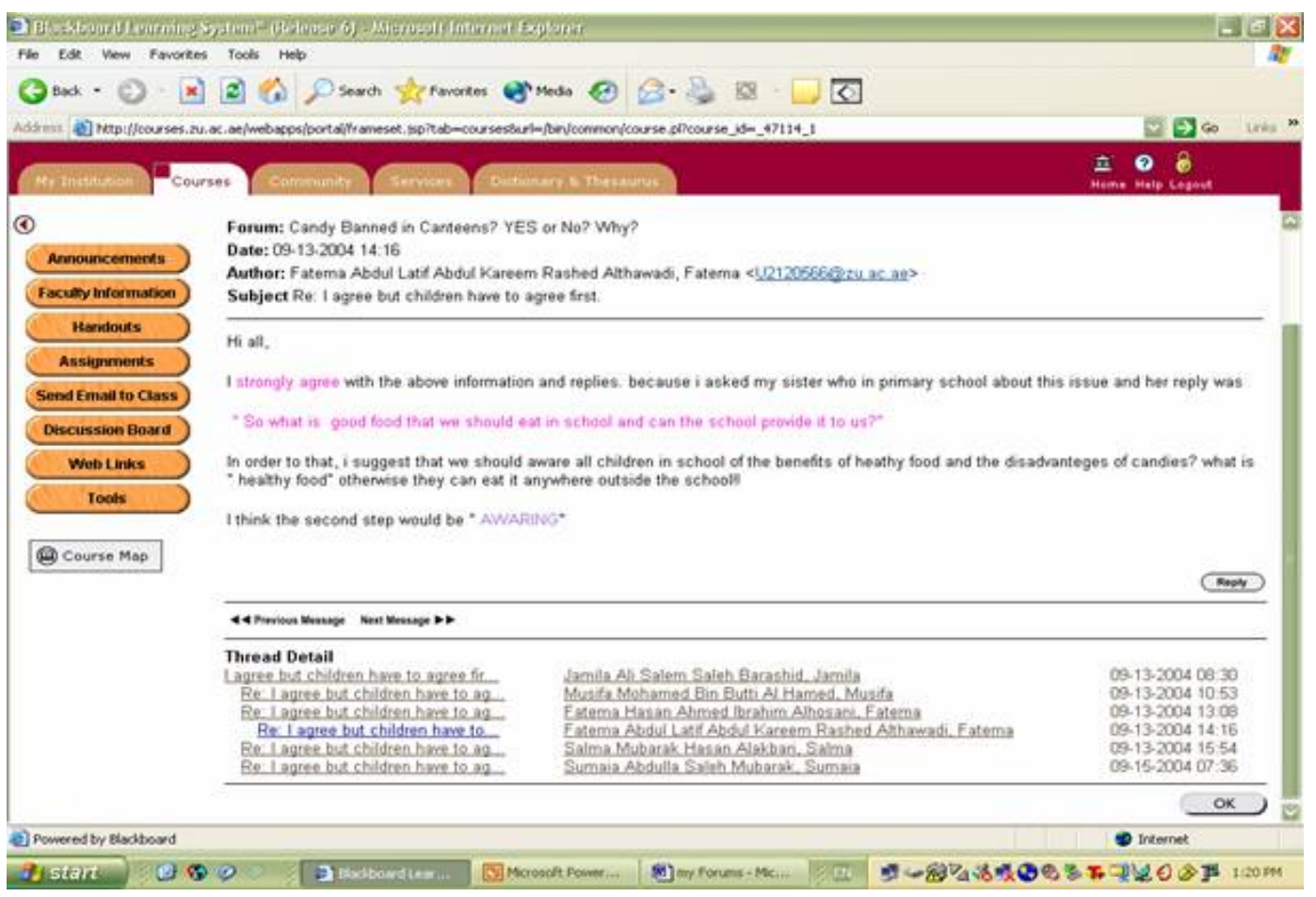

Many of the ideas come from an EXCELLENT source: $\underline{\text { http://www.shs.f2s.com/studytips.html }}$ 